\title{
The Effectiveness of the Real-case Online-based Learning on Nursing Care Plan Self-efficacy
}

\author{
Wantonoro Wantonoro ${ }^{1}$, Diyah Anita ${ }^{1}$, Mamnuah Mamnuah ${ }^{1 *}$ (D), Tuan Van Nguyen $^{2}$ (D) \\ ${ }^{1}$ Department of Nursing, Universitas 'Aisyiyah, Yogyakarta, Indonesia; ${ }^{2}$ Department of Nursing, Faculty of Nursing and \\ Technology, Can Tho University of Medicine and Pharmacy, Can Tho City, Vietnam
}

\begin{abstract}
Edited by: Mirko Zhivko Spiroski Citation: Wantonoro W, Anita D, Mamnuah M, Nguyen TV. The Effectiveness of the Real-case Online-based Learning on Nursing Care Plan Self-efficacy. Open Access Maced Med Sci. 2022 Feb 15; 10(G): 144-149. https://doi.org/10.3889/oamjms.2022.8347 Keywords: Online real case; Mix methods; Nursing "Correspondence: Mamnuah Mamnuah Depld-19 Correspondence: Mamnuah Mamnuah, Department

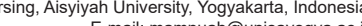
-mail: mamnuah@unisayogya.ac.i Revised: 23-Jan-2022 Accepted: 05-Feb-2022 Copyright: ๑ 2022 Wantonoro Wantonoro, Diyah Anita Mamnuah Mamnuah, Tuan Van Nguye Funding: This study is supported by The Association of Indonesian Nurse Education Center (AINEC Research Competing Interests: The authors have Award 2021) hors have declared that no competing interests exis
Open Access: This is an open-access article distribute NonCommercial 4.0 International License (CC BY-NC 4.0)
Non
\end{abstract}

\section{Introduction}

\section{Coronavirus Disease-19}

(COVID-19) pandemic has impacted negatively on various sectors of life, including the education sector such as the nursing learning process [1], [2], [3]. Various online learning innovations have been developed to support the achievement of nursing learning goals during the COVID-19 pandemic using the existing technology [4], [5]. Online learning has been adapted and supports the current nursing learning process [6]. However, there are limitations of the online learning [7]. One of those is the stress experienced by the students because of the internal and external factor [8], [9]. Therefore, active and patient-focused learning model are needed for the students with technology support without leaving the aspects of nursing values.

In general, nursing learning objectives emphasize the ability to demonstrate the value of caring professionally; altruism, human dignity, patient safety, and focus to provide the basic needs of the patients with holistic approach [6], [10]. Several studies reported that active learning strategies increase the cognitive level and increase the students' problem decision making skills [11], [12], such as problem base learning (PBL) [13], [14]. The studies shown that PBL has a positive effect on academic achievement [14], improves the students' analytical, and problem solving skills (critical thinking skills) [13].

Interaction and communication directly (offline) are the key to a successful PBL learning [15]. Online learning also involves practitioners as role models, performs role plays, and involves patients as a source of case-based learning which was reported to help students to obtain information actively, comprehensively and increase the students' satisfaction in an interactive learning process [16], [17]. Therefore, studying the implementation of an online-based PBL approach as a policy basis in implementing strategies or learning models that can facilitate students in achieving nursing learning goals in the era of technology and the current COVID-19 pandemic situation is needed. The study is aimed to determine the effectiveness of the online 
real case-based learning model on nursing care plan process and self-efficacy from the students' perspective.

\section{Methods}

\section{Study design}

The research used a mixed methods approach; explanatory sequential designs that start with a quantitative approach and continue with a qualitative approach to get comprehensive results [18], [19]. The quantitative approach with post-test control group design was conducted. Then, in-depth interview was conducted to explore the student experiences on real-case online-based learning on nursing care plan self-efficacy.

\section{Sample/participants}

One-hundred and fifty-seven students who took the Medical Surgical Nursing practice course at nursing study program, Aisyiyah University Yogyakarta, Indonesia, in the 2021/2022 academic year were included in the qualitative approach. We divided them into two groups: Intervention group (64 students) who were received the online learning with the real case involving the patient using zoom meet and, control group (93 students) who were received the online learning with paper-based case. Six students among the quantitative approach were participated in an additional description data collection by in-depth interview.

\section{Ethical consideration}

The research was carried out in accordance with the Helsinki Declaration Principles. Moreover, the study had been obtained approval from the Ethical committee (Number 1806/KEP-UNISA/VI/2021). All participants provided written informed consent before conducting the interviews.

\section{Data collection}

Self-efficacy questionnaire was used to measure three domains including; magnitude, strength, and generality of the students. The questionnaire used had been tested for the validity and reliability using Alpha Croncbach. The validity test of the 13 items showed $r$ count $>r$ table (0.12) and the results of the reliability test showed alpha 0.809 . Nursing care plan assessment university checklist sheet consisting of assessment, data analysis, determining nursing diagnoses, and interventions was used. The scoring of the assessment of understanding the nursing care consisted of 4 ranges, namely, (1) not appropriate,
(2) quite appropriate, (3) appropriate, and (4) very appropriate. The qualitative data were garnered through in-depth interviews (40-60 min long). We also employed field notes to capture conditions that emerged during the interview sessions. The interviews were conducted through video call and recorded based on the participants' informed consent. The trustworthiness of this qualitative study was ensured by four criteria: Credibility, dependability, transferability, and confirmability (16). Credibility was promoted by the researchers' prior engagement with the students who have experienced with online learning methods. Member checks were also used, that is, the results were brought back for the participants to confirm. Dependability and confirmability of the data were enhanced by keeping an audit trail, peer debriefing, using reflexive journals to record ideas and thoughts regarding whether the data were collected sufficiently, appropriateness of data coding and categorization in data collection and research meetings. Finally, transferability of the data was established by rich descriptions of the contextual conditions of the study phenomena.

\section{Data analysis}

Mann-Whitney's statistical approach was used to compare the differences of nursing care plan and self-efficacy between groups, and Colaizzi's method of data analysis was used for the additional data. The researchers conducted the data analysis from the recorded data, changed the results of the interviews from voice recordings into written form verbatim. Field notes on the participants and participant activities completed the results and it functioned as the addition to the analysis; including conducting member checking, triangulation, detailed transcription, systematic plan, and coding [20]. Then, it was transcribed word by word. The researchers then determined the keywords, categories, sub themes and themes. Finally, we collaborated the quantitative and qualitative findings for obtaining the comprehensive conclusions.

Table 1: Frequency distribution of the respondents

\begin{tabular}{lll}
\hline & Frequency $(\mathrm{n}=157)$ & Percentage \\
\hline Gender & 11 & \\
$\quad$ Male & 146 & 7.00 \\
$\quad$ Female & & 93.00 \\
Group & 64 & 40.80 \\
$\quad$ Intervention & 93 & 59.20 \\
$\quad$ Control & \\
\hline
\end{tabular}

\section{Results}

There were one-hundred and fifty-seven students involved in this study, 64 students (40.8\%) in the intervention group who participated in the online 
real case learning activities and as 93 (59.2\%) students participated in the online paper-based learning activities. Meanwhile, the distribution by sex was mostly female (93\%) (Table 1). The distribution of the frequency of self-efficacy by group mostly stated that the self-efficacy was in the moderate category $(66.9 \%)$ (Table 2). The bivariate test was used to determine the difference in nursing care plan scores and self-efficacy using the Mann-Whitney statistical approach obtained $p$-value for nursing care plans of 0.138 and self-efficacy of 0.450 (Table 3).

Table 2: Distribution of self-efficacy frequencies by group

\begin{tabular}{lllll}
\hline Self-efficacy & $\begin{array}{l}\text { Intervention group } \\
(\mathrm{n}=64)\end{array}$ & $\begin{array}{l}\text { Control group } \\
(\mathrm{n}=93)\end{array}$ & $\begin{array}{l}\text { Frequencies } \\
(\mathrm{n}=157)\end{array}$ & Percentage \\
\hline Moderate & 45 & 60 & 105 & 66.88 \\
High & 19 & 33 & 52 & 33.12 \\
\hline
\end{tabular}

Additional students' perspectives data; There were five themes identified by the students related to the real case online learning, including: 1) Opinions on learning, 2) the feelings experienced during learning, 3) learning benefits, 4) learning barriers, and 5) expectations of learning. The themes and the important finding are summarized in Table 4.

Table 3: The Mann-Whitney test of the Nursing care plan and self-efficacy

\begin{tabular}{lllll}
\hline Variable & $\mathrm{n}$ & Mean Rank & $\mathrm{z}$ & $\mathrm{p}$ \\
\hline Nursing care plan & & & & \\
$\quad$ Intervention & 64 & 85.34 & -1.48 & 0.138 \\
$\quad$ Control & 93 & 74.63 & & \\
Self-efficacy & & & & \\
$\quad$ Intervention & 64 & 76.30 & -0.756 & 0.450 \\
$\quad$ Control & 93 & 80.85 & & \\
\hline
\end{tabular}

\section{Discussion}

This study found there was no difference in the score of the nursing care planning process, self-efficacy between the online real case group and, paper-based case methods group. In addition, several findings from additional students' perspectives were found by in-depth interview, including barrier, expectation, and technology support system needs. Advance technology was improved and, COVID-19 pandemic situation "force" the acceleration or modification and, adaptation and also adoption in the learning process for all generations including the lecturers and the students. It is noticed that there are limitations to use the online learning, so it is necessary to evaluate the online learning. It was supported by the previous studies which reported virtual interaction with the patients can be done but did not significantly provide more learning outcomes compared to paper-based or offline learning. The studies informed that online learning as a supplement in offline learning [21], [22]. It was implied that the offline learning with face-to face meeting was still important.
There are various obstacles in the online learning that cause the learning process to be less than optimal. Some studies reported that the internet connection and facilities owned by the students and, also tutors were the important factors that become a "barrier" in online learning [7], [23]. It was supported by the additional student perspectives findings of this study which reported that internet connection is an "obstacle," thus, our findings indicate a limitation "barrier." Internet connectivity had varying degrees across different countries, and influenced the online learning [24]. However, on the other hand, there are positive responses by the participants that the modification of activities carried out using online real cases provides variations in learning, including interesting learning, interactive lesson and can be felt directly because it uses cases that can be seen directly.

In terms of the preparation of the nursing care plan process, there is no difference between groups, this also generally occurs in students' self-efficacy towards abilities in nursing which are relatively the same in both groups. Self-efficacy is a belief/confidence that must be possessed by the students to succeed in the learning process. The high self-efficacy in nursing learning will help to narrow the gap between theory and practice and, increase the students' confidence in carrying out activities related to health services. The majority of the respondents in both groups have a moderate self-efficacy category. It is supported by the previous research which informed that most of the nursing students had high selfefficacy when using online learning methods [25]. In contrast, another study confirmed that the majority of the nursing students had poor overall self-efficacy as well as domain wise online learning self-efficacy [26]. Another study reported online-offline learning was found effective in improving nursing students' knowledge and attitudes [27]. It implied the varied outcome among the study of online learning for students' self-efficacy. Based on this study, confidently concluded that the real case learning method give benefit and positive experienced for nursing students' self-efficacy.

Self-efficacy is a cognitive variable that affects attitudes and behavior. Perceived self-efficacy can be influenced by direct experience, vicarious experience, or verbal persuasion. Previous research suggests that individuals with high levels of self-efficacy show confidence in their abilities and have perseverance to achieve the expected learning goals [28]. Self-efficacy is a good indicator to predict the performance of nursing students in clinical practice [29]. Self-efficacy can also be interpreted as belief in one's ability to take action to manage future situations [30]. Increased self-efficacy can foster independence and self-confidence [31]. The previous research has shown that job satisfaction and intention to stay in the profession are influenced by a person's level of self-efficacy [32], [33]. 
Table 4: Five themes were identified by the students related to the real case online learning

\begin{tabular}{|c|c|c|}
\hline Themes & Sub themes & Students' perspectives \\
\hline $\begin{array}{l}\text { Opinions on } \\
\text { learning }\end{array}$ & $\begin{array}{l}\text { Advanced } \\
\text { learning during } \\
\text { pandemic }\end{array}$ & $\begin{array}{l}\text { "It can help me more to visualize the patient's case. The method is good because it can provide an overview of the health problems } \\
\text { experienced by the patient. Then the process is also more interactive compared to the previous method." (P1) } \\
\text { "Interesting because usually when practicing in college, the wound is treated with panthoms, if this is directly, it's like measuring the } \\
\text { depth of the wound and measuring the length of the wound, so the atmosphere is different, seeing as measuring the wound directly } \\
\text { compared to the panthom." (P2) } \\
\text { "I think the learning process is good because we can see the real case, the actual incident." (P3) } \\
\text { "This method is interesting because usually we only study cases, if this method is real, we can see the wound and its treatment. } \\
\text { Interested to see with this Real Case Online method, usually only cases, in the form of words, sentences. If the real media is like this, } \\
\text { we can see directly like this." (P4) }\end{array}$ \\
\hline $\begin{array}{l}\text { The feelings } \\
\text { experienced } \\
\text { during learning }\end{array}$ & Positive feeling & $\begin{array}{l}\text { "This method is very impressive, l'm excited, I'm really interested in yesterday's lesson, yesterday there should still be many students } \\
\text { who still want to ask questions but because the contract time is } 2 \mathrm{~h} \text {, so many want to ask the patient again. Many are excited, and } \\
\text { follow yesterday's learning method." (P6) } \\
\text { "Alhamdulillah, I feel happy, because this is my } 1^{\text {st }} \text { time participating in a real case online course and I am even happier that way, for the } \\
\text { learning is more interesting and easier to understand, maybe if all this time, if we go through cases in the form of sentences like that, } \\
\text { we are confused and if we want to ask questions, we are also confused. If it's through a real case, if we don't know, we can ask for the } \\
\text { handler, it's more real, we can see it like that." (P4) }\end{array}$ \\
\hline Learning Benefits & $\begin{array}{l}\text { Physiology } \\
\text { and, } \\
\text { Knowledge } \\
\text { aspect }\end{array}$ & $\begin{array}{l}\text { "This real case online method is carried out directly, the practice is direct, so later if I practice in the hospital, it will be better because I } \\
\text { can still remember the material." (P2) } \\
\text { "Perhaps during this time of a pandemic, the practice is also limited, so we can add knowledge even though it is virtual, but we can all } \\
\text { learn in real." (P4) } \\
\text { "Add knowledge, add insight about some topicals. There is also something that is often used, doesn't always use NS or NaCl to treat } \\
\text { wounds. Because we see right away, we are used to seeing, we will try, after that we have confidence and believe we can do it." (P5) }\end{array}$ \\
\hline Learning Barriers & $\begin{array}{l}\text { Time and, } \\
\text { Signal } \\
\text { limitation }\end{array}$ & $\begin{array}{l}\text { "It's just that there's not enough time, so there should be a lot that I still want to ask." (P6). } \\
\text { "The only problem is, the signal is intermittent, so the sound from the patient is not too loud when the voice is heard." (P3) }\end{array}$ \\
\hline $\begin{array}{l}\text { Expectations of } \\
\text { learning }\end{array}$ & $\begin{array}{l}\text { Method } \\
\text { developing }\end{array}$ & $\begin{array}{l}\text { "There will be many online, so maybe later the learning method will be made like this. Then, for example, what is the skill today, is it an } \\
\text { infusion, So it's the same as yesterday with wound care, so there is a resource person then he practices directly putting infusions and } \\
\text { through zoom, so it seems that it is more conveyed and effective." (P6) } \\
\text { "My hope is that in the future, if for example, it can't go offline, this online real case seems to be more frequent then also like the cases } \\
\text { that are raised are more diverse." (P1) }\end{array}$ \\
\hline
\end{tabular}

There are several suggestions to improve self-efficacy of the nursing students, including: 1) The students should have the opportunity to practice clinical skills in a skills laboratory under the supervision of a clinical educator; 2) the students should receive ongoing and effective feedback throughout their studies; 3) clinical educators should provide a variety of clinical experiences for the nursing students; and 4) nursing students should be encouraged to act independently and under the indirect supervision of clinical educators when they reach a certain level of competence [34].

Self-efficacy in the offline learning is higher than in the online learning using the conference meeting method. However, the previous studies stated that there was no significant difference in the final results of nursing competence. A study showed that selfefficacy decreased in online learning with conference meetings is influenced by: 1) The internet connection; 2) support in learning; and 3) decreased interest in sharing information among fellow learning participants. However, studies report that conference meetings are a good alternative to gain insight and help in creating variety in clinical learning [35].

\section{Research limitations}

There are several limitations in this study including nursing care process that did not reach the implementation and evaluation stages. As well as differences in time, geography, and networks that allow for different learning experiences from each participant, it also leads to different perceptions in the comparison of the two methods.

\section{Conclusion}

The online learning using paper based and real cases provides the students with relatively the same experience in terms of preparing nursing care plans and students' self-efficacy in nursing care. However, the real case online learning provides a different atmosphere, which is more interesting, interactive interaction with the patients directly and provides positive experience for the students. Infrastructure/facilities (internet availability and stability) are important factors in the online learning process. The online real case learning is recommended as an alternative learning method that is more interesting and interactive which involves patients and students' interaction and direct supervisors. Further research on the mixed learning method process in nursing care; offline and online real case, comprehensive and interdisciplinary approaches are recommended.

\section{Acknowledgment}

We would like to thank the patients who have participated in real case online learning this research.

\section{Authors' Contributions}

Study conception and design: $\mathrm{M}$ and $\mathrm{W}$; Data collection: DCA, M, and W; Data analysis and 
interpretation: DCA, M, and W; Drafting of the article: W and DCA; Critical revision of the article: TVN.

\section{References}

1. Dewart G, Corcoran L, Thirsk L, Petrovic K. Nursing education in a pandemic: Academic challenges in response to COVID-19. Nurse Educ Today. 2020;92:104471-71. https://doi. org/10.1016/j.nedt.2020.104471

PMid:32502723

2. Ilankoon IMP, Kisokanth G, Warnakulasuriya SS. COVID-19: Impact on undergraduate nursing education in Sri Lanka. J Public Health Res. 2020;9(Suppl 1):1916. https://doi. org/10.4081/jphr.2020.1916 PMid:33409248

3. Gaffney MK, Chargualaf KA, Ghosh S. COVID-19 disruption of nursing education and the effects on students' academic and professional confidence. Nurse Educ. 2021;46(2):76-81. https:// doi.org/10.1097/NNE.0000000000000986

PMid:33587411

4. Alqahtani N, Innab A, Bahari G. Virtual education during COVID-19: Exploring factors associated with E-learning satisfaction among saudi nursing students. Nurse Educ. 2021;46(2):E18-22. https://doi.org/10.1097/ NNE.0000000000000954

PMid:33234836

5. Walsh JA. Switching strategies: Using telehealth as an innovative virtual simulation teaching method. Nurse Educ. 2020;45(6):330. https://doi.org/10.1097/NNE.0000000000000908 PMid:32756264

6. Konrad S, Fitzgerald A, Deckers C. Nursing fundamentals supporting clinical competency online during the COVID-19 pandemic. Teach Learn Nurs. 2021;16(1):53-6. https://doi. org/10.1016/j.teln.2020.07.005

PMid:32837448

7. Li W, Gillies R, He M, Wu C, Liu S, Gong Z, et al. Barriers and facilitators to online medical and nursing education during the COVID-19 pandemic: Perspectives from international students from low- and middle-income countries and their teaching staff. Hum Resour Health. 2021;19(1):64. https://doi.org/10.1186/ s12960-021-00609-9

\section{PMid:33980228}

8. Mamnuah M. Stress and efforts by students in learning during Covid-19 pandemic. J Aisyah. 2021;6:267-72.

9. Norhidayah AA, Hamdoni KP. Coping style, anxiety level, organizational support, and work commitment of educators during the COVID-19 pandemic in the Philippines: A mixedmethods study. Belitung Nurs J. 2021;7(4):267-76.

10. Ernawati E, Bratajaya CN. Senior nurses' perceptions of essential soft skills for novice nurses in a private hospital in Jakarta, Indonesia: A phenomenological study. Belitung Nurs J. 2021;7(4):1549.

11. Tyo MB, McCurry MK. An integrative review of clinical reasoning teaching strategies and outcome evaluation in nursing education. Nurs Educ Perspect. 2019;40(1):11-7. https://doi. org/10.1097/01.NEP.0000000000000375

PMid:30095730

12. Scheckel M. Designing courses and learning experiences. In: Teaching in Nursing: A Guide for Faculty. St. Louis, Missouri: Elsevier; 2016. p. 159-85.

13. Servant VF, Schmidt HG. Revisiting foundations of problem-based learning: Some explanatory notes. Med Educ. 2016;50(7):698-701. https://doi.org/10.1111/medu.12803 PMid:27295470

14. Sayyah M, Shirbandi K, Saki-Malehi A, Rahim F. Use of a problem-based learning teaching model for undergraduate medical and nursing education: A systematic review and metaanalysis. Adv Med Educ Pract. 2017;8:691-700.

15. Wosinski J, Belcher AE, Dürrenberger $Y$, Allin AC, Stormacq $C$ Gerson L. Facilitating problem-based learning among undergraduate nursing students: A qualitative systematic review. Nurse Educ Today. 2018;60:67-74.

16. Akcaoglu M, Lee E. Increasing Social Presence in Online Learning through Small Group Discussions. Vol. 17. The International Review of Research in Open and Distributed Learning; 2016.

17. Weidlich J, Bastiaens TJ. Explaining social presence and the quality of online learning with the SIPS model. Comput Hum Behav. 2017;72:479-87.

18. Dowding $D$. Best practices for mixed methods research in the health sciences John W. Creswell, Ann Carroll Klassen, Vicki L. Plano Clark, Katherine Clegg Smith for the office of behavioral and social sciences research; qualitative methods overview jo moriarty. Qual Soc Work. 2013;12(4):541-5.

19. Leslie C, Marcella NS. Mixed Methods in Health Sciences Research: A Practical Primer. Thousand Oaks, California: SAGE; 2015.

20. Gunawan J. Ensuring trustworthiness in qualitative research. Belitung Nurs J. 2015;1(1):10-1.

21. Fatani TH. Student satisfaction with videoconferencing teaching quality during the COVID-19 pandemic. BMC Med Educ. 2020;20(1):396. https://doi.org/10.1186/ s12909-020-02310-2 PMid:33129295

22. Klemenc-Ketis Z, Cagran B, Dinevski D. Evaluating the difference between virtual and paper-based clinical cases in family medicine undergraduate education. Adv Med. 2018;2018:1408450. https://doi.org/10.1155/2018/1408450 PMid:29568779

23. Thapa P, Bhandari SL, Pathak S. Nursing students' attitude on the practice of e-learning: A cross-sectional survey amid COVID-19 in Nepal. PLoS One. 2021;16(6):e0253651. https:// doi.org/10.1371/journal.pone.0253651

PMid:34166444

24. Cullinan J, Flannery D, Harold J, Lyons S, Palcic D. The disconnected: COVID-19 and disparities in access to quality broadband for higher education students. Int J Educ Technol Higher Educ. 2021;18(1):26

25. Harefa EY, Simamora E, Hia GT. Description of Selt-efficasy Indonesian Nursing Students (Indonesia Language). Bachelor Thesis. Universitas Pelita Harapan; 2020.

26. Tiwari SK, Srivastava SP. Self-efficacy of online learning among nursing students during COVID-19 pandemic. 2021;8(9):7.

27. Moon H, Hyun HS. Nursing students' knowledge, attitude, self-efficacy in blended learning of cardiopulmonary resuscitation: A randomized controlled trial. BMC Med Educ. 2019;19(1):414.

28. Robb M. Self-efficacy with application to nursing education: A concept analysis. Nurs Forum. 2012;47(3):166-72. https://doi. org/10.1111/j.1744-6198.2012.00267.x PMid:22861653

29. Zengin N, Pınar R, Akinci AC, Yildiz H. Psychometric properties of the self-efficacy for clinical evaluation scale in Turkish nursing students. J Clin Nurs. 2014;23(7-8):976-84. https://doi. org/10.1097/NNE.0000000000000954

PMid:23876212 
30. Stump GS, Husman J, Brem SK. The nursing student selfefficacy scale: Development using item response theory. Nurs Res. 2012;61(3):149-58. https://doi.org/10.1097/ NNR.0b013e318253a750

PMid:22551989

31. Bandura A. Perceived self-efficacy in cognitive development and functioning. Educ Psychol. 1993;28(2):117-48.

32. Duggleby W, Cooper D, Penz K. Hope, self-efficacy, spiritual wellbeing and job satisfaction. J Adv Nurs. 2009;65(11):2376-85. https://doi.org/10.1111/j.1365-2648.2009.05094.x

PMid:19737323
33. Lee TW, Ko YK. Effects of self-efficacy, affectivity and collective efficacy on nursing performance of hospital nurses. J Adv Nurs. 2010;66(4):839-48. https://doi. org/10.1111/j.1365-2648.2009.05244.x

PMid:20423371

34. Alavi NM. Self-efficacy in nursing students. Nurs Midwifery Stud. 2014;3(4):e25881. https://doi.org/10.17795/nmsjournal25881 PMid:25741520

35. Secco L, Bulman D, Wilson K. Pilot evaluation of a virtual clinical excursion (VCE) among senior nursing students: Part 2 qualitative perspectives and learning style. Can J Nurs Inf. 2012;7(4):1-8. 